Www.jmscr.igmpublication.org

Impact Factor 5.84

Index Copernicus Value: 83.27

ISSN (e)-2347-176x ISSN (p) 2455-0450

crossref DOI: https://dx.doi.org/10.18535/jmscr/v5i7.86

Journal Of Medical Science And Clinical Research

\title{
Mean Platelet Volume as an Independent Risk Factor for Acute Myocardial Infarction and Its Short Term Prognostic Significance
}

\author{
Authors \\ Dr Ajitha Kesi Chellappan', Dr Sajan Christopher ${ }^{2}$ \\ ${ }^{1}$ Assistant Professor, Dept of Internal Medicine, Government Medical College, Thiruvananthapuram \\ ${ }^{2}$ Assistant Professor, Dept of Internal Medicine Government Medical College, Thiruvananthapuram, Kerala \\ Corresponding Author
}

Dr Sajan Christopher MD

Email: sajan.christopher@yahoo.com

\begin{abstract}
Background of study: The biological events that occur in the Coronary system immediately preceding acute coronary syndromes are still unclear. However platelets are definitely involved, and changes in platelet structure may be a casual factor in producing a thrombus in the coronary artery. Platelet activation, by favouring thrombus formation and coronary artery occlusion is thought to play a key pathogenic role in acute myocardial infarction ${ }^{1}$

It has been shown that platelet size, measured as mean platelet volume (MPV) correlates with their reactivity ${ }^{3}$. Circulating platelets are heterogeneous in size density and reactivity ${ }^{10}$. Platelet age \& size are independent determinants of platelet function ${ }^{5}$. Mean platelet volume is positively associated with indicators of platelet activity including expression of glycoprotein $1 \mathrm{~b}$ and glycoprotein IIb/IIIa receptor on many studies. Elevated MPV has been recognised as independent risk factor for myocardial infarction,

In acute stages of platelet activation, an increase in platelet volume might be a result of a change in fragmentation pattern of megakaryocyte.

The goal of the study was to assess MPV in patients with acute myocardial infarction (AMI) admitted within 3 hours of chest pain, and its short term prognostic significance.
\end{abstract}

\section{Introduction}

It is well known that platelet rich thrombus is central to the pathology of MI and acute coronary syndrome. Platelet activation and aggregation ignite the process of coagulation and inflammation. It has been observed that large platelets are more reactive ${ }^{9}$. High mean platelet volume (MPV) has been shown to associated with AMI, acute ischemic stroke ${ }^{2}$, acute mesenteric ischemia ${ }^{11}$ and secondary HN. Increased platelet volume is associated with higher risk for suffering acute coronary event, In 2001 Endler $^{6}$ et al demonstrated that with MPV more than 1.6 times control had significant increased risk for MI after adjusting for confounding risk factors for $\mathrm{MI}^{6}$. MPV was increased in patients who $\operatorname{died}^{7}$. Moreover Martin ${ }^{7}$ et al showed that MPV did not correlate with traditional ischemic heart disease risk factors such as hypertension dyslipedemia fibrinogen, WBC count or plasma viscosity . Therefore increased MPV is believed to be an independent risk factor for $\mathrm{MI}^{6}$. In a study on 100 
patients with chest pain, Glud ${ }^{16}$ et al showed that there was $12 \%$ fall in platelet count followed by $36 \%$ increase. Initially there was $2 \%$ increase in MPV followed by $8 \%$ increase. Further fall in platelet count and increase in MPV correlated with infarct size (maximum activity of LDH) and might reflect consumption of platelets.

Kish $\mathrm{YT}^{8}$ et al in his study showed that $60 \%$ of MI patients were lying in the area of high platelet volume compared to the $13 \%$ of control.

Angiotensin 11 type 1 receptor antagonist such as Losartan used in the treatment of hypertension also elicit antinflammatory and antiaggregation property which was mediated by Losmetabolite EXP3179 by inhibiting COX-2 mRNA up regulation and COX dependent TXA2 and PGF2 ${ }^{0 \mathrm{c}}$ generation $^{14}$.

Losartan's therapeutic effects on platelet size has been reported by Jegroop ${ }^{14}$ et al but not yet confirmed. Little is known about the effect of aspirin $^{4}$ and other platelet aggregation inhibitors on MPV. In a small study of 30 patients, sharp et al found no effect on MPV. However whether interaction with platelet aggregation inhibitors or other drugs are beneficial for patients with high MPV remains to be evaluated.

In a study Schulthesis HP et al investigated the activation status of circulating platelets by directly measuring the membrane activation marker $\left(\mathrm{CD}_{62}\right.$ and $\mathrm{CD}_{63}$ with the Dusseldorf 111 flow cytometry in 22 patients with diagnosis of AMI during $48 \mathrm{hrs}$ period following the acute event. The number of activated marker positive sample platelets was significantly increased in post MI patients. The platelet volume was concomitantly increased $(12.1+/-2.4 \mathrm{fl}$ compared to $8.3+/-1.6 \mathrm{fl}$ in the control group) significant creatinine kinase elevation and decrease in platelet count was found in non survivor subset which concluded that predominantly large platelets continue to circulate in activated state after MI. This study provides direct evidence to the assumption that an increased thrombotic potential becomes operative in vivo in MI.
We propose that MPV may be an important adjunct in the management of AMI. However studies ${ }^{12}$ have shown conflicting results

The present study was under taken to evaluate the MPV in patients with AMI in comparison to healthy controls.

\section{Aim}

1. To assess MPV in patients with acute myocardial infarction admitted with in 3 hours of chest pain.

2. To assess the short term prognostic value of MPV.

3. To find out the correlation between MPV and platelet count

\section{Materials \& Methods}

120 patients admitted with acute myocardial infarction within 3 hours of chest pain without traditional risk factors who underwent thrombolytic therapy in department of Medicine for a period of 6 months were selected for the study.

\section{Inclusion Criteria}

1. Patients admitted to ICCU with diagnosis of acute ST elevation Myocardial infarction admitted within 3hours of chest pain.

2. patient above the age of 20years and less than 80years.

3. Thrombolysed.

\section{Exclusion Criteria}

1. Patients not having typical ECG charges,

2. 2. presence of septicaemia, CRF, patients with CRF on Erythropoietin therapy, history of or clinical evidence of hyperthyroidism,

3. patients with traditional risk factors like diabetes mellitus, hypertension, metabolic syndrome, dyslipidemia, smokers and malignancy

4. any other condition that cause ST elevation like aortic aneurysm, vasospasum, LV aneurysm were excluded. 


\section{Study Design}

Patients admitted with AMI were selected for the study, age and sex matched controls from the same population who did not have a past history of MI or stroke was enrolled for this study. Histories to exclude factors that cause MPV elevation were taken. Blood samples for MPV estimation were collected in ethylene diamine tetra acetate (EDTA) vacutainer and processed immediatly. Platelet size tends to increase at room temperature on storage in first two hours and subsequently remain relatively stable for up to eight hours ${ }^{14}$. Dastjerdi ${ }^{13}$ et al, assured that MPV measurement can be accurate if sample is analysed within one hour of collection and care was taken to adhere to the time frame to minimise in vitro increase in platelet volume. MPV was analyzed in Sysmex 3000 automatic analyzer. Clinical signs of left heart failure was assessed at performed in all patients to assess the extent of MI and left ventricular status. All patients were followed for one week to assess outcomes like reinfarction, left ventricular dysfunction and death and a repeat echocardiogram was done on all patients before discharge.

Stastical analysis is done using SPSS version 21. Biochemical and physical variables were expressrd as MEAN+_SD. Students t- test and chi square test were used to compare categorical variables. A p value of less than 0.01 is considered significant.

\section{Results}

Out of 120 acute myocardial infarction cases, 101 were males and 18 were females. Male predominance was noted $(84 \%)$

Table 1:Sex wise distribution of study group

\begin{tabular}{|l|c|c|}
\hline Sex & No: of cases & Percentage \\
\hline Male & 101 & 84.17 \\
\hline Female & 19 & 15.83 \\
\hline
\end{tabular}
the time of admission. Echocardiogram was

Fig 1: Sex wise distribution of study group

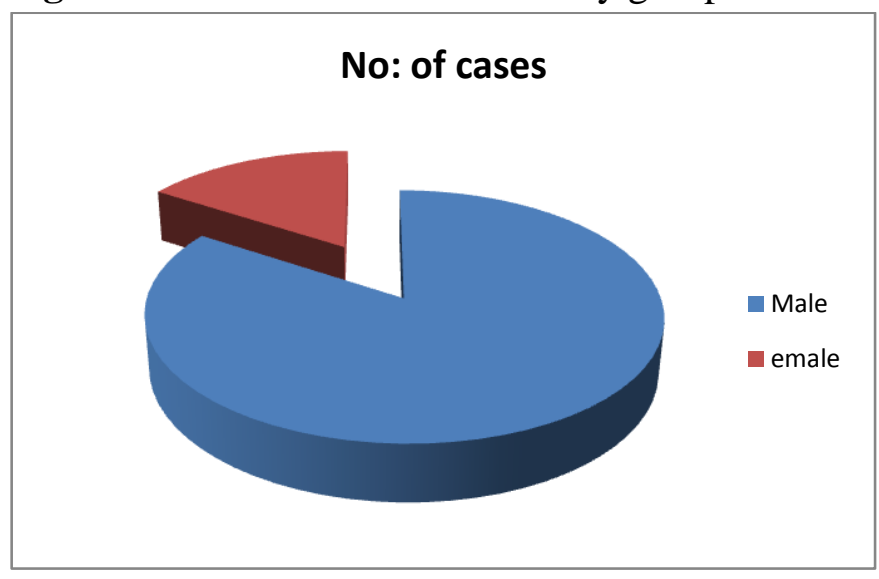

Table 2: Age wise distribution of the study group

\begin{tabular}{|l|c|c|}
\hline $\begin{array}{l}\text { AGE } \\
\text { (Years) }\end{array}$ & $\begin{array}{c}\text { Number of } \\
\text { Patients } \mathrm{n}=120\end{array}$ & Percent \\
\hline $20-29$ & 0 & 0 \\
\hline $30-39$ & 6 & 5 \\
\hline $40-49$ & 24 & 20 \\
\hline $50-59$ & 34 & 28.33 \\
\hline $60-69$ & 29 & 24.17 \\
\hline $70-79$ & 27 & 22.5 \\
\hline
\end{tabular}

Fig 2: Age wise distribution of study groups

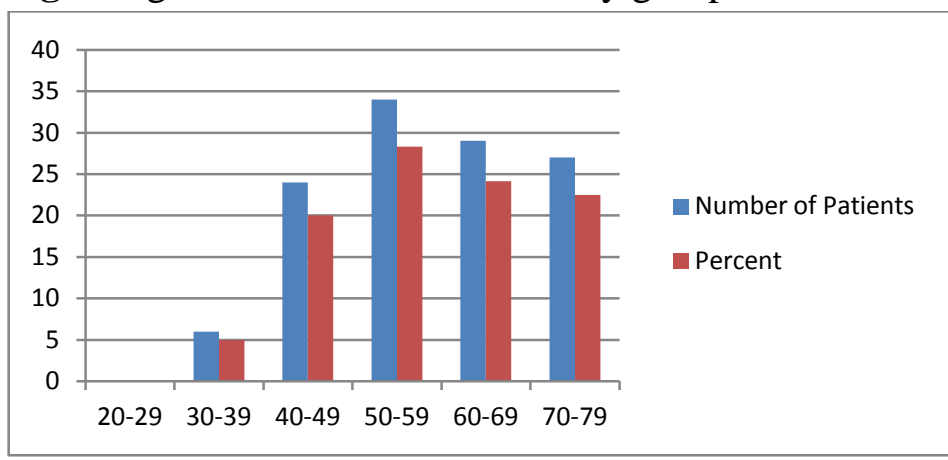

Table 3: Comparison of the study variables between control and study group

\begin{tabular}{|c|c|c|}
\hline Variables & $\begin{array}{l}\text { Study group } \\
(\mathrm{n}=120)\end{array}$ & $\begin{array}{c}\text { Control group }( \\
n=54)\end{array}$ \\
\hline Mean systolic BP & $126.4+\_4.08$ & $122.3+\_4.66$ \\
\hline Mean diastolic BP & $82.7+\_3.33$ & 80.22+_6.09 \\
\hline MeanFBS & $86.28+\_8.42$ & $84.33+88.26$ \\
\hline $\begin{array}{ll}\text { Mean } & \text { Serum } \\
\text { creatinine } & \end{array}$ & $0.66+0.16$ & $0.66+0.12$ \\
\hline $\begin{array}{ll}\begin{array}{l}\text { Mean } \\
\text { cholestrol }\end{array} & \text { Serum } \\
\end{array}$ & $164.87+25.76$ & $160.7+222.8$ \\
\hline Mean LDL & $87.1+\_15.88$ & $84.8+\_27.8$ \\
\hline Mean HDL & 47.96+_6.03 & $44.3+\_7.8$ \\
\hline
\end{tabular}




\begin{tabular}{|l|c|c|} 
Mean Triglyceride & $128.8+\_45.46$ & $146.24+\_66.25$ \\
\hline Mean BMI & $22.21+\_1.03$ & $21.03+\_1.27$ \\
\hline
\end{tabular}

The mean age of patients was 50.42+-13.6 years and that of the control was5 $7.22+-13.3$ years.

Table 4: Distribution of mean MPV in the study group

\begin{tabular}{|l|c|c|c|}
\hline & $\begin{array}{c}\text { Mean MPV } \\
\text { +_SD(fl) }\end{array}$ & $\begin{array}{c}\text { Minimum } \\
\text { MPV(fl) }\end{array}$ & $\begin{array}{c}\text { Maximum } \\
\text { MP(fl) }\end{array}$ \\
\hline Case & $10.83+\_2.18$ & 7 & 14 \\
\hline Control & $8.12+\_1.2$ & 6.6 & 8.9 \\
\hline
\end{tabular}

Fig 3: Distribution of mean MPV in the study group

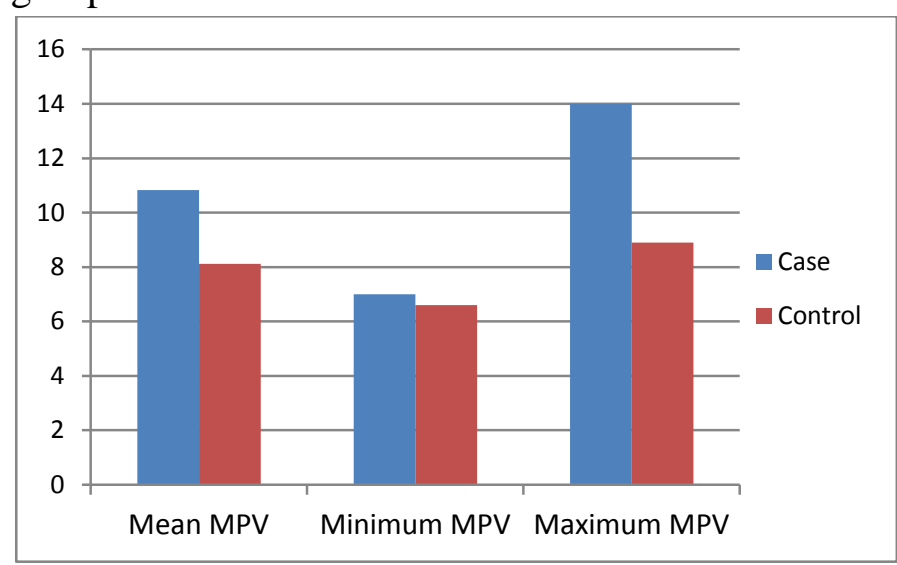

(Standard 1.814)

Mean value of MPV in AMI group was 10.23+218. fl compared to $8.12+-1.2 \mathrm{fl}$ in control (p value 0.003 ) suggesting that MPV was definitely elevated in AMI.

In the control group all patients had MPV less than 8.9fl and MPV less than 9fl was present only in $3 \%$ of patients with acute myocardial infarction. So MPV of 9fl was taken as cut off to distinguish patient from control. By using MEAN-WHITNEY two sample test for comparison $p$ value was 0.001.Comparison between patients and controls showed that patients had significantly elevated MPV (( (. ROC (Receiver operating characteristic) analysis of the MPV values revealed that the area under the curve (AUC) to be $88.9 \%$ (95\% CI,84.5\%-95.6\%) with a $\mathrm{p}$ value of 0.000003 . Diagnostic test evaluation with a cut off 9.26 fl with a sensitivity of $78 \%$,specificity of $88 \%$ ,and a positive predictive value of $89.46 \%$. It was observed that for one femtolitre increase in MPV there was decrease in platelet count by 12,000 in the AMI group)))

Table 5: Comparison of MPV with sex of the study

\begin{tabular}{|l|l|}
\hline Sex & Mean MPV \\
\hline Male & $10.8+\_2.4$ \\
\hline Female & $10.9+\_1.6$ \\
\hline
\end{tabular}

Fig 4: Comparison of MPV with sex of the study

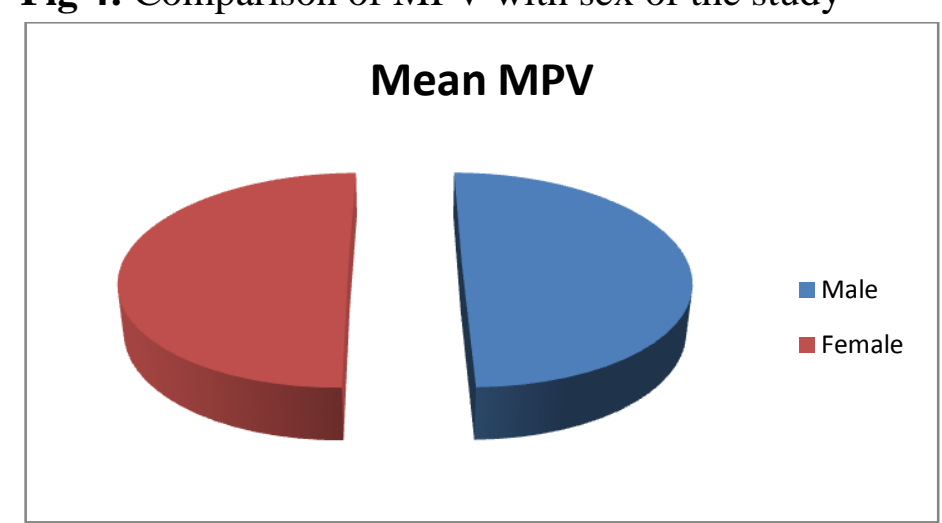

There was no relation between MPV and sex of the patient

\section{Complications}

Percentage of distribution of sample according to reinfarction

\begin{tabular}{|l|c|c|c|}
\hline Reinfarction & $\begin{array}{c}\text { No: of cases. } \\
\mathrm{n}=120\end{array}$ & percent & control \\
\hline Present & 6 & $5 \%$ & 0 \\
\hline Absent & 114 & $95 \%$ & 54 \\
\hline
\end{tabular}

Fischer Exact test shows that $\mathrm{p}$ value is 0.17

The control and reinfarction group were comparable

Table 6: Comparison of MPV with complications.

\begin{tabular}{|l|l|l|l|l|}
\hline Complication & $\begin{array}{l}\text { mean MPV } \\
\text { +_SD }\end{array}$ & & $\mathrm{t}$ & p value \\
\hline & CASE & CONTROL & & \\
\hline REINARCTION & $11.1+\_1.9 f 1$ & $10.1 \mathrm{fl}$ & & $<0.001$ \\
\hline
\end{tabular}

\begin{tabular}{|l|l|l|l|l|}
\hline $\begin{array}{l}\text { LET } \\
\text { VENTRICULAR } \\
\text { DYSFUNCTION }\end{array}$ & & & \\
\hline MILD & $10.9+1.2 \mathrm{fl}$ & $10.1+\_1.1 \mathrm{fl}$ & $<0.001$ \\
\hline MODERATE & $10.8+\_2.1 \mathrm{fl}$ & $10.1+\_1.1 \mathrm{fl}$ & $<0.001$ \\
\hline SEVERE & $11.23+2.9 \mathrm{fl}$ & $10.1+\_1.1 \mathrm{fl}$ & $<0.001$ \\
\hline \multicolumn{5}{|l|}{} \\
\begin{tabular}{|l|l|l|l|}
\hline DEATH & $11.2 \_f l$ & $10.1+\_1.1 \mathrm{fl}$ & \\
\hline
\end{tabular}
\end{tabular}


Fig 5: Distribution of MPV with complications

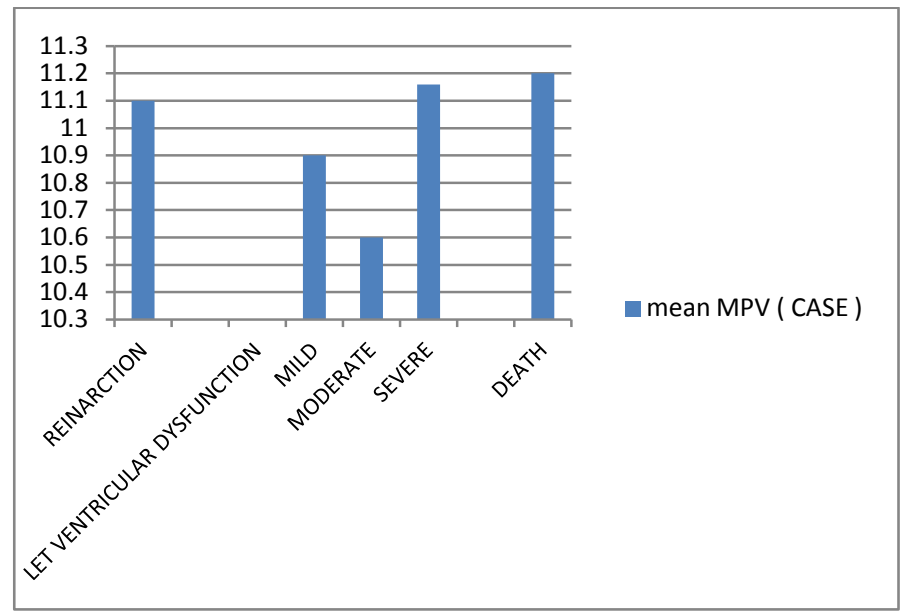

There is significant correlation between reinfarction and MPV ( $\mathrm{p}$ value $<0.001$. There is significant correlation between left ventricular dysfunctions and MPV ( $p$ value $<0.001$ ). Only one death was reported, and value of MPV in the dead patient was 11.2fl while in others MPV was 10.8 fl (not statistically significant).

Table 7: Comparison of mean MPV with region of Myocardial infarction

\begin{tabular}{|l|c|}
\hline $\begin{array}{l}\text { Region of Myocardial } \\
\text { infarction }\end{array}$ & Mean MPV \\
\hline AWMI & $11.32+\_2.1$ \\
\hline IWMI & $10.3+\_1.1$ \\
\hline IWMI+RVMI & $10.4+\_1.2$ \\
\hline Lateral wall MI & $10.3+\_1.6$ \\
\hline
\end{tabular}

Fig 6: Distribution of mean MPV with region of Myocardial infarction

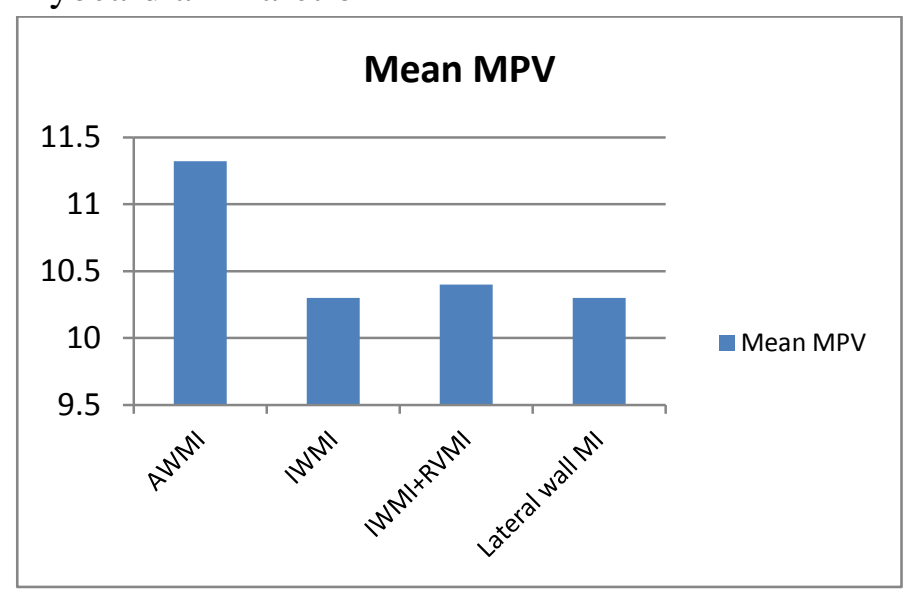

MPV was significantly elevated in anterior wall myocardial infarction compared to inferior wall MI or inferior with right ventricular MI

Table 8: Comparison of Platelet count between case and study

\begin{tabular}{|l|l|l|}
\hline & Case & Control \\
\hline Platelet count & 2.26 & 3.04 \\
\hline
\end{tabular}

The mean platelet count in AMI group 2.26/cumm Compared to $3.04 \mathrm{~L} /$ cumm, $\mathrm{P}$ value is 0.003 suggesting thrombocytopenia in the initial phase of acute myocardial infarction. \%. It was observed that for one femtolitre increase in MPV there was decrease in platelet count by 12,000 in the AMI group)))

Fig 7: Distribution of Platelet count between case and study

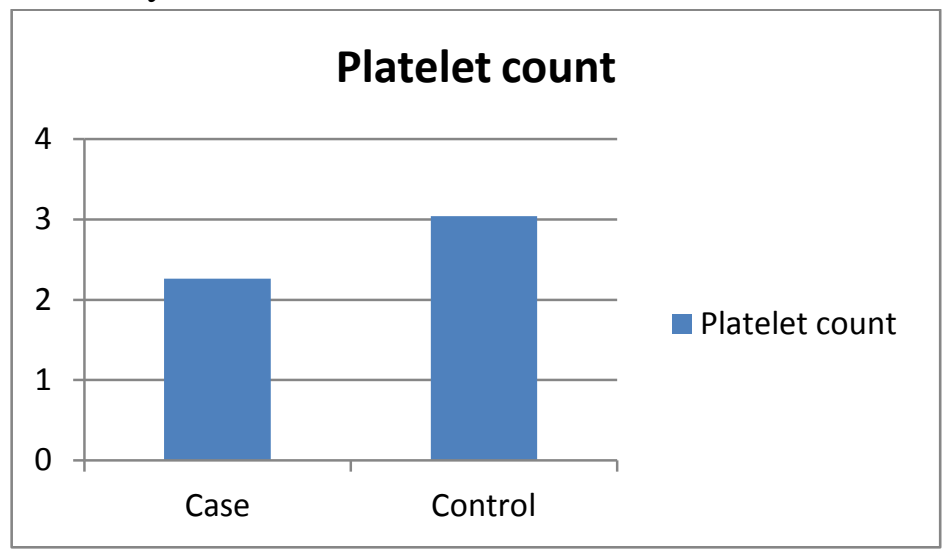

\section{Discussion}

After the rupture of arteriosclerotic plaque in a coronary artery, platelets play a crucial role in the subsequent thrombus formation, leading to myocardial infarction. Increased MPV an indicator of platelet reactivity may represent a risk factor for myocardial infarction ${ }^{14}$

However this hypothesis is still controversial and most studies addressing the role of MPV were done comparing patients suffering from myocardial infarction with healthy control in western countries. To the best of our knowledge, no such similar study has been done in this part of the country 
In this study MPV of patients with acute myocardial infarction were compared with non myocardial infarction patients.

The mean age of patients with myocardial infarction in 57 years. The maximum number of patients 57/119 (47\%) of them were between 50.59 years. It correlates with the pattern of coronary artery disease reported in India, which is between 51-60 years, which is a decade earlier compare with the age incidence in developed countries . The exact reason for this premature coronary artery disease in Indian subjects are clearly not known smoking, genetic factors, life style and many other things are postulated.

The incidence of myocardial infarction is more in males $(84 \%)$ compared to female $15 \%$. This finding correlates with decades of observational studies, that there is an excess risk in males compared to premenopausal females. At least part of the apparent protection against coronary artery disease is their relatively higher HDL level compared to men. After menopause HDL level falls in concert with increased Coronary artery disease risk.

Reinfarction in our AMI group patients was 5\%. Up to $3-4 \%$ of patients who have undergone thrombolytic therapy and received aspirin is found to have reinfarctions. Significance is that death, congestive hea rt failure and arrhythmias are early complication of reinfarction ${ }^{14}$.

The cause of reinfarction are many but one of the latest finding is that some of the patients with myocardial infarction is found to have aspirin resistance.

Platelet count in myocardial infarction group is 2.26 lakhs per cubic mm compared to $3.041 / \mathrm{cmm}$ in the control. This difference was found to be statistcally significant with a $\mathrm{p}$ value of 0.0000037 . These findings correlated with previous study done by, Glud $\mathrm{T}^{16}$ et al showing a fall in platelet count initially in myocardial infarction. This might reflect consumption of platelets during acute myocardial infarction. It was deducted from the study that for each femtoliter increase in mean platelet volume platelet count decreased by 12000 in the initial phase of acute myocardial infarction.

Mean value of MPV in patients with acute myocardial infarction is $10.83 \mathrm{fl}$ compared to $8.12 \mathrm{fl}$ in control ( $\mathrm{p}$ value is 0.003 ) MPV was significantly elevated in myocardial infarction group. This was the most important point revealed by the study. Our study findings indicate that increased platelet volume is associated with a higher risk of developing an acute coronary event. In the control group no value of mean platelet volume was more than $8.9 \mathrm{fl}$ and the value less than $9 \mathrm{fl}$ was present in 5 patients in the myocardial infarction group. This contributed to only $3 \%$ in myocardial infarction group. Therefore MPV above 9fl may be taken as probably one of the criteria for diagnosing acute myocardial infarction similar to other criteria like in cardiac enzymes.

Males with myocardial infarction had a mean platelet volume of $10.8 \mathrm{fl}$ while females had 10.9fl, which was not statistically significant. So there is no relationship between mean platelet volume and sex of the patients with myocardial infarction.

Mean platelet volume was significantly elevated in anterior wall myocardial infarction compared to inferior wall or lateral wall myocardial infarction. This point confirms the study done by Kishk $\mathrm{YT}^{16}$ et al that in acute myocardial infarction increased mean platelet volume is related to size and site of infract. Study done by Glud $\mathrm{T}^{16}$ et al showed that increased mean platelet volume correlated with infarct size (maximum activity of L.D.H).

Our study confirms the fact that mean platelet volume was significantly elevated in reinfarction following $\mathrm{AMI}^{7}$.

Mean platelet volume was significantly elevated in left ventricular dysfunction following AMI. This finding confirms the fact that in myocardial infarction, patients with severe cardiac failure had larger platelet volume, which reflects either increased platelet activation or increased numbers of large, hyper aggregate platelets ${ }^{7}$. 
Only one patient succumbed to death in this study. Cause of death was extensive anterior wall myocardial infarction with left ventricular dysfunction with pulmonary oedema. This was not statistically significant due to poor sample sizes, possibly correlation with mortality could be established by improved sample size.

\section{Limitation of the study}

An average life span of platelet is 7-10 days .The vast majority of platelets sampled at the time of hospital admission for AMI would have been circulating before the event. Martin $\mathrm{JF}^{8}$ demonstrated that MPV remains elevated 6 weeks after acute MI .

As automated blood counts are now freely available every physician should have a glance at the mean platelet volume reading (which is not at all observed by any doctor) to detect somebody who may be prone for an acute coronary event so that proper preventive measures may be taken for these individuals.

\section{Conclusion}

Patients with increased mean platelet volume of more than $9 \mathrm{fl}$ are at higher risk for acute myocardial infarction. These patients can easily be identified during routine haematological analysis and could possibly benefit from preventive treatment. A new criterion is being proposed for the diagnosis of acute myocardial infarction. In a suspect patients with acute coronary syndrome MPV more than 9fl is suggestive of myocardial infarction.

A fall in platelet count occurred in initial phase of acute myocardial infarction. It was calculated from the study was platelet count decreased by 12000 for every one femtoliter increase in mean platelet volume.

\section{Ethical Issues}

No ethical issues or financial grants involved in this study.

\section{References}

1. Massberg S, Schulz C, Gawaz M. Role of platelets in the pathophysiology of acute coronary syndrome. Semin Vasc Med 2003;3:147-62.

2. Greisenegger S, Endler G, Hsieh K et al. Is elevated mean platelet volume associated with a worse outcome in patients with acute ischemic cerebrovascular events? Stroke 2004;35:1688-91.

3. Martin JF, Trowbridge EA, Salmon G et al. The biological significance of platelet volume: its relationship to bleeding time, platelet thromboxane B2 production and megakaryocyte nuclear DNA concentration. Thromb Res 1983;32:443-60.

4. Erhart S, Beer JH, Reinhart WH. Influence of aspirin on platelet count and volume in humans. Acta Haematol 1999;101:140-4.]

5. Bath PM, Butterworth RJ. Platelet size: measurement, physiology and vascular disease. Blood Coagul Fibrinolysis 1996;7:157-61.]

6. Endler G, Klimesch A, Sunder-Plassmann $\mathrm{H}$ et al. Mean platelet volume is an independent risk factor for myocardial infarction but not for coronary artery disease. Br J Haematol 2002;117:399404.]

7. Martin, J. F., Bath, P. M. and Burr, M. L. (1991). Inuence of platelet size on outcome after myocardial infarction. Lancet, 338, 1409-11.25. Sharpe, P. C. and Trinick, T. (1993). Mean platelet volume in diabetes mellitus. Q J Med, 86, 739-42.

8. Martin, J. F., Plumb, J., Kilbey, R. S. and Kishk, Y. T. (1983). Changes in volume and density of platelets in myocardial infarction. Br Med J (Clin Res Ed), 287, 456-9.

9. Chu, S. G., Becker, R. C., Berger, P. B., Bhatt, D. L., Eikelboom, J. W., Konkle, B., Mohler, E. R., Reilly, M. P. and Berger, J. S. (2010). Mean platelet volume as a predictor of cardiovascular risk: a 
systematic review and meta-analysis. J thromb Haemost, 8, 148-56.

10. Bath, P. M. and Butterworth, R. J. (1996).

Platelet size: measurement, physiology and vascular disease. Blood Coagul Fibrinolysis, 7, 157-61.

11. Bilgic, I. C., Gelecek, S., Mahir Ozmen, M. and Kasapoglu, B. (2014). $\square$ e association of elevated mean platelet volume with the outcome of acute mesenteric ischemia. Blood Coagul Fibrinolysis.

12. Damodar, S., Ganesh, K. V. and Murthy, S. (2008). Mean platelet volume does not predict .risk of myocardial infarction or coronary artery disease in Indian patients. Platelets, 19, 80-1.

13. Dastjerdi, M. S., Emami, T., Naja $\square$ an, A. and Amini, M. (2006). Mean platelet volume measurement, EDTA or citrate? Hematology, 11, 317-9.

14. Jagroop, I.A. \& Mikhailidis, D.P. (2000) Angiotensin II can induce and potentiate shape change in human platelets: effect of losartan. Journal of Human Hypertension, $14,581-585$.

15. Sharpe, P.C., Desai, Z.R. \& Morris, T.C. (1994) Increase in mean platelet volume in patients with chronic renal failure treated with erythropoietin. Journal of Clinical Pathology, 47, $159-161$.

16. Glud T,Schmidt EB,Kristensen SD Arnfred T. (1986)Platelet number and mean platelet during myocardial infarction in relation to infarct size.Acta Med Scand,220(5):401-5. 